University of Nebraska - Lincoln

DigitalCommons@University of Nebraska - Lincoln

Historical Materials from University of

Nebraska-Lincoln Extension

Extension

2005

Monitoring Soybean Disease and Insect Infection Patterns in

Nebraska

Xingchun Chen

University of Nebraska-Lincoln, xchen4@unl.edu

Ron Roeber

University of Nebraska-Lincoln, RROEBER1@UNL.EDU

Follow this and additional works at: https://digitalcommons.unl.edu/extensionhist

Chen, Xingchun and Roeber, Ron, "Monitoring Soybean Disease and Insect Infection Patterns in Nebraska" (2005). Historical Materials from University of Nebraska-Lincoln Extension. 2073.

https://digitalcommons.unl.edu/extensionhist/2073

This Article is brought to you for free and open access by the Extension at DigitalCommons@University of Nebraska Lincoln. It has been accepted for inclusion in Historical Materials from University of Nebraska-Lincoln Extension by an authorized administrator of DigitalCommons@University of Nebraska - Lincoln. 


\title{
Monitoring Soybean Disease and Insect Infection Patterns in Nebraska
}

\author{
Xingchun Chen and Ron Roeber
}

\begin{abstract}
Plant diseases, insects, and insect vectored viruses can do extensive damages to host plants and result in severe yield losses. It is reported that overall about $15 \%$ of the U.S. crop production is lost annually to infectious crop diseases despite the fact that American agricultural producers are using cutting-edge disease control technology and pesticide products, and adapting newly bred disease-resistant crop cultivars and hybrids. This Nebraska Crop Surveillance Network project has accomplished three objectives. First, it uses advanced computer, database and network technology to automate experimental field data collection, processing and centralization storage processes, thus relieving research staff from tedious and redundant work while also reducing the likelihood of human error during the data collection and transcription processes. Second, it tracks soybean disease infection patterns under different management, environmental and soil conditions during the growing season in Nebraska. Third, it produces an online graphical visualization system based on the near realtime data collected from the experimental field to simulate, monitor and predict soybean disease infection patterns. These graphical representations of patterns are intended to help convey disease infection related concepts and disease control decision-making information to agriculturalists. The online tracking system is designed to help Nebraska farmers to make the right decisions on their daily agricultural practices, such as choosing the right planting date and applying the right pesticide to minimize plant damage and maximize yield potential. We use a Zope web server, a MySQL relational database, and a graphic rendering product, ZGDChart to build this data visualization system which completely automates data gathering and storage processes and enables users to observe a graphical representation of plant disease infection patterns during the growing season in Nebraska under different management and environmental conditions.
\end{abstract}

Index Terms-Agriculture, Diseases, Microorganisms, Monitoring

\section{INTRODUCTION}

Plant diseases, insects, and insect vectored viruses can do extensive damages to host plants and result in severe yield losses. Throughout history, severe crop failures have been associated with numerous deadly famines [1]. Although

$\mathrm{X}$. Chen is with the University of Nebraska, Lincoln, NE 68583 USA (phone: 402-472-5512; fax: 402-472-00253; e-mail: xchen4@ unl.edu).

R. Roeber is with the University of Nebraska, Lincoln, NE 68583 USA (email:rroeber1@unl.edu). governments annually invest a lot of time and money on plant disease control, their efforts are not always successful. It is reported that approximately $15 \%$ of the U.S. crop production is lost annually to infectious crop diseases, despite the fact that American agricultural producers are using a host of modern disease control technology including pesticide products, and new disease-resistant crop cultivars and hybrids. In the U.S. state of Georgia alone, it is estimated that in 2002 plant yield loss due to disease infection and disease control costs together reached to $\$ 576.65$ million U.S. dollars (Georgia Agricultural Statistics Service 2002) [2].

At least 50,000 plant disease species have been identified and new diseases are being discovered every year [1]. Cooperative extension specialists and teachers at the University of Nebraska are working hard to educate agricultural producers and campus students how to identify, prevent and control plant disease infection to reduce the damage to host plants and minimize crop yield losses. However, lack of educational and monitoring tools are able to use real data from the experimental field to simulate disease infection patterns makes it difficult for the extension specialists and teachers to explain, and agricultural producers and students in the classroom to understand the related concepts, which in turn hinder farmers as they attempt to make correct farming decisions.

The Nebraska Crop Surveillance Network, funded by the Nebraska Soybean Board, is a project for research and education. The objectives of this project are as follows. First, automate experimental field data collection, processing and storage processes to relieve experimental personnel of daily tedious work and also reduce possible human error during the data processing. Second, study how soybean disease infection patterns vary under different management, environmental and soil conditions during the growing season in Nebraska. Third, use advanced computer technology to develop a visualization tool to simulate, monitor and predict disease infection pattern to help disease infection related concept understanding and disease control decision making. This project is designed to help Nebraska farmers to make correct decisions in their daily agricultural practices, such as choosing the right planting date and applying the right pesticide to minimize plant damage and maximize yield potential.

In this project, we use relational database and network technology to completely automate the data gathering and storage processes. We adapt MySQL database technology, a Zope web server and a graphic rendering product, ZGDChart to build a system that enables users to dynamically simulate, monitor, and predict disease infection patterns under different management and environmental conditions. 
In the rest of this article, we briefly describe the design and configuration of computer and network technology we have used to build it from a software engineer's point of view.

\section{FIELD EXPERIMENTAL DESIGN}

Soybean, an important Nebraska produce, is used as the test crop which is experimented on two planting dates (the conventional planting date and early planting date) and 19 experimental locations. The observation variables include soil temperature, air temperature, relative humidity, leaf wetness, precipitation, and the number and height of healthy and infectious plants. We record crop damages by two plant insects (bean leaf beetle and soybean aphid), two viruses (bean pod mottle and soybean mosaic), and 19 diseases that are further classified into three categories: plant foliar diseases, seedling diseases, and stem and root diseases. The foliar diseases include bacteria blight, septoria brown spot, soybean rust, frogeye leaf spot, downy mildew, and bacterial pustule; the stem and root diseases consist of pod and stem blight, phyophthora stem and root rot, charcoal rot, brown stem root, anthracnose, sudden death syndrome, stem canker, sclerotinia stem rot, and rhizoctonia; and the seedling diseases include rhizoctonia, pythium, phytophthora, fusarium, and unknown seedling diseases.

\section{DATA COLLECTION}

The leaf wetness, environmental and soil data are gathered from two different sources. For an experimental site within a reasonable distance from a weather station connected to the High Plain Regional Climate Center (HPRCC) weather server, we use a Python script and cron. On a daily basis, the cron process invokes the Python script that logs into the HPRCC to fetch, process and store the corresponding data into a centralized MySQL server. For experimental site beyond a reasonable distance to the HPRCC covering area, we install environmental and soil sensors in the field. Hourly, the sensors take the measurements and save the data in attached dataloggers. Then the data is transferred by a hand held device to an Apache web server and finally processed and saved by a Python script into the MySQL server.

Plant disease, insect, and insect vectored virus infection data are collected manually. On a weekly basis during crop growing season, a research technician goes out to each field and randomly selects a sample area where the number and height of various disease, insect and virus infected plants and healthy plants are recorded and entered through a web form into the same database server.

\section{SYSTEM DESIGN}

The system is designed for ease of use and to be accessible to individuals having a range of skills and expertise. To use the system, an individual needs only an Internet accessible computer and a web browser. On the left panel from the project front page (Figure 1), a user is able to select and simulate one of the four parameters: plant insects, plant diseases, plant viruses and environmental factor. For example, after selecting the environmental factor from the left panel, an interface on the right panel prompts the user to make further customized refinements to simulation time interval (daily, weekly or monthly), location, starting date and ending date. Once a request is submitted, the system fetches the corresponding data entries from the MySQL database and feeds them into a ZGDChart computer graphrendering package which renders the data and displays the results graphically. Figure 2 shows a daily air temperature, soil temperature, relative humidity and precipitation of an experimental field at Beatrice in Cage County in 2004.



Fig. 1. Input page for environmental and soil information simulation

Follow the same procedure, a user is able to simulate and monitor plant disease, insect and virus infections. Figure 3 and Figure 4 show the soybean leaf beetle and aphid populations, soybean seedling stage, stem and root disease levels under different environmental and management conditions at the same experimental site in Burt County in 2004.
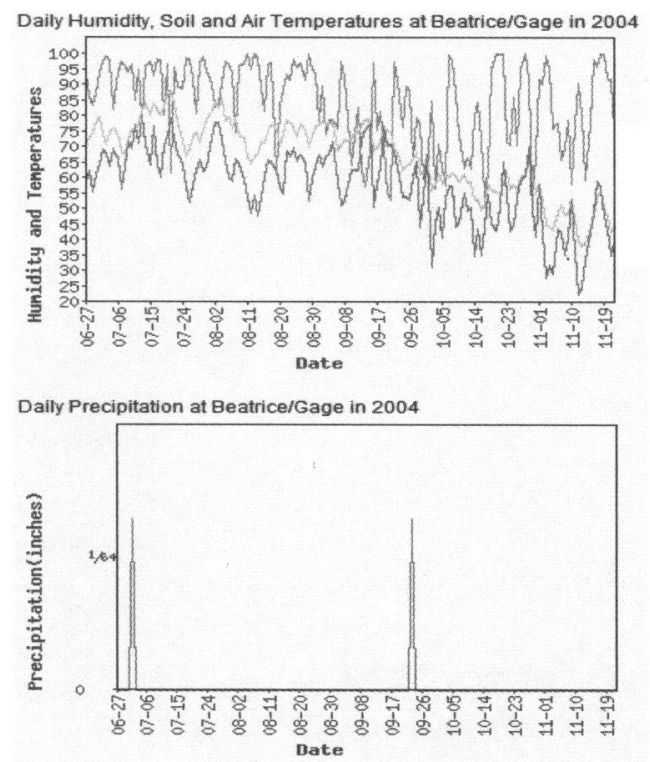

Fig. 2. Weather information at Beatrice in 2004

In order to compare and study the effect of various management and environmental factors on disease infection patterns, the application is able to generate a side-by-side graph that compares disease infection patterns between any two selections a user chooses. Figure 5 shows a sample graph 
which compares soybean stem and root disease infection patterns for two locations which are in Burt and Gage counties respectively in 2004 . The comparison provides the researchers and agricultural producers helpful information to make the right disease controlling decisions.
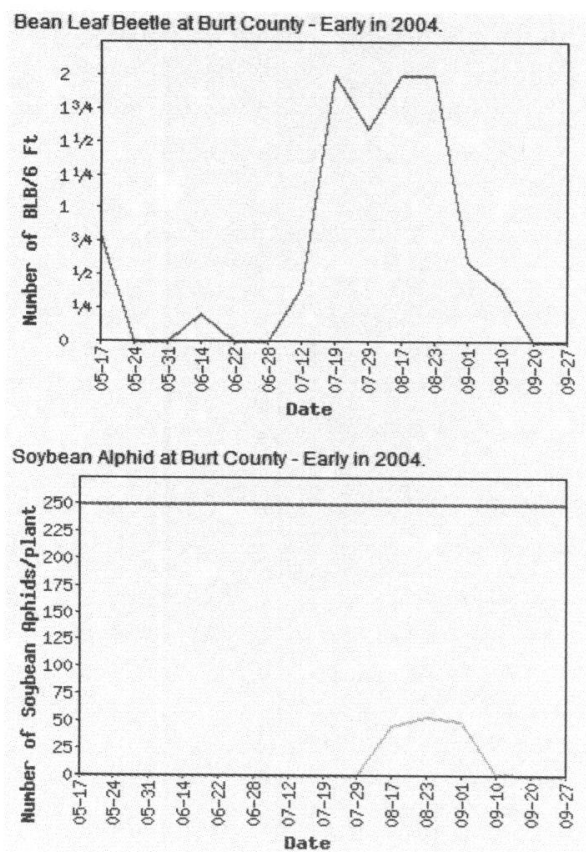

Fig. 3. Soybean leaf beetle and aphid of a conventionalplanting-date during the growing season in Burt County in 2004.
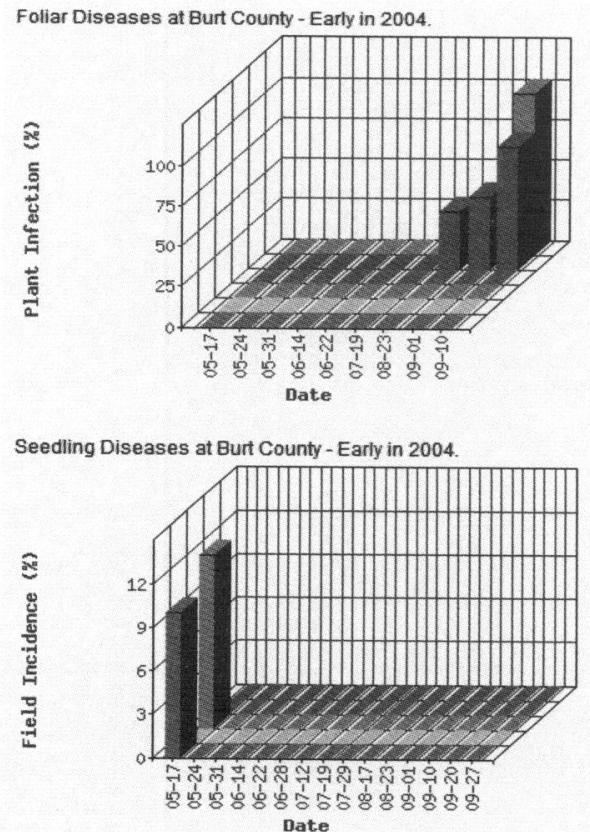

Fig. 4. Soybean seedling, stem and root diseases of an early planting date during the growing season in Burt County in 2004


Fig. 5. Comparison of soybean foliar diseases, and stem and root diseases in Burt and Gage counties in Nebraska in 2004

\section{TECHNOLOGY USED}

The system is built in a Zope [3] web server with a MySQL relational database [4] support. Zope, as an open source web application server, is written in Python and built for content management systems and custom applications. To support graph rendering, we use a Zope add-in product, ZGDChart [5]. The ZGDChart is able to communicate with and get data from a relational database, a Python script and other resources. It can generate different types of charts such as line chart, pie chart and histogram, and produce 2-D and 3$\mathrm{D}$ effect. Additionally, almost every component of the chart such as the title, Y-label and color scheme can be dynamically configured during the graph rendering process.

\section{REFERENCES}

[1] Plant Pathology

http://www.hcs.ohio-state.edu/mg/manual/path.htm

[2] Georgia Plant Disease Loss Estimates, http://pubs.caes.uga.edu/caespubs/pubcd/SB41-05.htm

[3] Open Source Zope Web Server http://www.zope.org/

[4] Open Source MySQL Relational Database, http://www.mysql.com/ 